\title{
VASOPRESSIN TREATMENT IMPROVES SYSTEMIC HEMODYNAMICS WITHOUT COMPROMISING MESENTERIC PERFUSION DURING REOXYGENATION OF ASPHYXIATED NEWBORN PIGLETS: A DOSE RESPONSE STUDY
}

\author{
R.S. Gill ${ }^{1}$, D. Cheung ${ }^{2}$, T.-F. Lee ${ }^{3}$, N. Manouchehri ${ }^{1}$, D. Bigam ${ }^{1}$, P.-Y. Cheung ${ }^{1,3}$, B. Dicken ${ }^{1}$ \\ ${ }^{1}$ Surgery, ${ }^{2}$ Faculty of Medicine and Dentistry, ${ }^{3}$ Pediatrics, University of Alberta, Edmonton, AB, Canada
}

Background: Asphyxia is associated with over 1-million newborn deaths worldwide. Asphyxiated newborns may present with myocardial dysfunction and hypotension. Vasopressin, an endogenous vasoconstrictive hormone, is commonly administered in adults with refractory shock. Anecdotal concerns regarding mesenteric vasoconstriction has limited its use in newborns.

Objective: We hypothesize that vasopressin administration will improve systemic hemodynamics without compromising mesenteric perfusion during reoxygenation of severely asphyxiated newborn piglets.

Methods: Thirty-three piglets (1-4 days-old) were instrumented for continuous monitoring of cardiac output, systemic arterial pressures (SAP) and superior mesenteric arterial (SMA) flow. After stabilization, normocapnic alveolar hypoxia (10-15\% oxygen) was instituted for $2 \mathrm{~h}$ followed by reoxygenation with $100 \%$ $(0.5 \mathrm{~h})$ and $21 \%(3.5 \mathrm{~h})$ oxygen. Piglets were block-randomized to receive vasopressin-infusion following $2 \mathrm{~h}$ of reoxygenation, at one of three doses $(0.005,0.01,0.02 \mathrm{mg} / \mathrm{kg} / \mathrm{h})$ or placebo (normal saline, control) for an additional $2 \mathrm{~h}$. Blood samples and intestinal tissue were collected for analysis. Statistical analysis was performed with ANOVA.

Results: All piglets demonstrated hypotension (SAP 27-31 mmHg) and decreased SMA flow (42-62 \% of baseline) at the end of hypoxia. Following $2 \mathrm{~h}$ of reoxygenation, vasopressin infusion at $0.02 \mathrm{mg} / \mathrm{kg} / \mathrm{h}$ caused significant improvement of SAP versus controls $(\mathrm{P}<0.05)$ with no significant effects on cardiac function. Left ventricular lactate was significantly decreased in all vasopressin treated piglets compared to controls $(\mathrm{P}<0.05)$. Mesenteric oxygen delivery, vascular resistance and intestinal lactate levels were similar among groups.

Conclusion: We are first to demonstrate that post-resuscitation vasopressin infusion improves systemic hemodynamics without compromising mesenteric perfusion in asphyxiated newborn piglets following reoxygenation. 